\title{
Coastal Impacts of the March 11th Tohoku, Japan Tsunami in the Galapagos Islands
}

\author{
Patrick Lynett, ${ }^{1}$ Robert Weiss, ${ }^{2}$ Willington Renteria, ${ }^{3}$ Giorgio De La Torre Morales, ${ }^{3}$ Sangyoung Son, ${ }^{1}$ \\ Maria Elizabeth Martin Arcos, ${ }^{4,5}$ and Breanyn Tiel Macinnes 5,6
}

\begin{abstract}
On March 11, 2011 at 5:46:23 UTC (March 10 11:46:23 PM Galapagos Local Time), the $M_{w}$ 9.0 Great East Japan Earthquake occurred near the Tohoku region off the east coast of Japan, spawning a Pacific-wide tsunami. Approximately 12,000 km away, the Galapagos Islands experienced moderate tsunami impacts, including flooding, structural damage, and strong currents. In this paper, we present observations and measurements of the tsunami effects in the Galapagos, focusing on the four largest islands in the archipelago; (from west to east) Isabela, Santiagio, Santa Cruz, and San Cristobal. Access to the tsunami affected areas was one of the largest challenges of the field survey. Aside from approximately ten sandy beaches open to tourists, all other shoreline locations are restricted to anyone without a research permit; open cooperation with the Galapagos National Park provided the survey team complete access to the Islands coastlines. Survey locations were guided by numerical simulations of the tsunami performed prior to the field work. This numerical guidance accurately predicted the regions of highest impact, as well as regions of relatively low impact. Tide-corrected maximum tsunami heights were generally in the range of 3-4 m with the highest runup of $6 \mathrm{~m}$ measured in a small pocket beach on Isla Isabela. Puerto Ayora, on Santa Cruz Island, the largest harbor in the Galapagos experienced significant flooding and damage to structures located at the shoreline. A current meter moored inside the harbor recorded relatively weak tsunami currents of less than $0.3 \mathrm{~m} / \mathrm{s}(0.6 \mathrm{knot})$ during the event. Comparisons with detailed numerical simulations suggest that these low current speed observations are most likely the result of data averaging at 20 -min intervals and that maximum instantaneous current speeds were considerably larger. Currents in the Canal de Itabaca, a natural waterway between Santa Cruz Island and a smaller island offshore, were strong enough to displace multiple 5.5-ton navigation buoys. Numerical simulations indicate
\end{abstract}

1 Department of Civil and Environmental Engineering, University of Southern California, Los Angeles, CA 90089-2531, USA. E-mail: plynett@usc.edu

2 Department of Geosciences, Virginia Tech, 4044 Derring Hall (0420), Blacksburg, VA 24061, USA.

3 Coastal and Environmental Studies Section, Insitituto Oceanográfico de la Armada Guayaquil (INOCAR), Puerto Ayora, Galapagos Islands, Ecuador.

4 AMEC, 2101 Webster Street, Oakland, CA 94612, USA.

5 Department of Earth and Space Sciences, University of Washington, Box 351310, Seattle, WA 98195-1310, USA.

6 Institute of Seismology and Volcanology, Hokkaido University, N10W8 Kita-ku Sapporo, Hokkaido 060-0810, Japan. that currents in the Canal de Itabaca exceeded $4 \mathrm{~m} / \mathrm{s}$ ( $\sim 8$ knots), a very large flow speed for a navigational waterway.

\section{Introduction}

On March 11, 2011 at 5:46:23 UTC (March 10 11:46:23 PM Galapagos Local Time), the $\mathrm{M}_{\mathrm{w}} 9.0$ Great East Japan Earthquake generated a locallydevastating and Pacific-wide tsunami. Tsunami impacts in Japan were widely reported through the popular media, and field survey data indicate runup elevations in excess of $40 \mathrm{~m}$ (Mori et al., 2011). While the tsunami affected areas throughout the Pacific (see for example BorRERo et al., 2012; WILSON et al., 2012, and other papers in this special volume), the effects were generally insignificant compared to the ruin experienced in Japan.

During the tsunami event, information from the Pacific Tsunami Warning Center (PTWC) was used by the Regional Tsunami Information Center operated by the Galapagos Marine Research Center (CIMAG) at the Insitituto Oceanográfico de la Armada Guayaquil (INOCAR) of Ecuador to recommend actions to both local and national authorities early in the morning on March 11th (local time). Recommendations included the evacuation of coastal zones and suspension of all maritime activities in the Islands. Ships were moved offshore to depths of $200 \mathrm{~m}$, and all vessels in transit were forbidden to enter any harbor. According to government reports 20,260 people were evacuated from coastal towns in the Galapagos and temporarily relocated inland to higher ground. This was the second tsunami evacuation of coastal areas in the Galapagos; the first being roughly 1 year earlier following the February 27th 
2010 earthquake in Chile. Most of the evacuees returned to their homes early in the morning of March 12th (local time), when local authorities indicated it was safe to do so. There were no fatalities due to the tsunami in the Islands, although there was widespread flooding with isolated pockets of severe damage. In this paper, we will first describe the geophysical setting of the Islands, followed by a detailed presentation of the coastal field surveys which is the first comprehensive tsunami field survey in the Galapagos Islands. Finally, tsunami-induced current observations near the Islands are examined, and detailed numerical simulations are used to complement and assist in the explanation of the data.

\section{Geophysical Setting}

The Galapagos are a chain of volcanic islands located in the central-western portion of the Pacific Ocean, (Fig. 1). The islands have formed over an active hot spot beneath the Nazca plate (WERNER et al., 2003), which continues the formation of new islands. Due to the eastward movement of this plate, the relative location of each island is related to its age with the older islands at the eastern end of the chain (BAILEY 1976). The Galapagos archipelago is comprised of a total of 233 islands, islets, and rocks, with the largest islands being Isabela, Santiago, Santa Cruz, and San Cristobal. All of these islands are located over a shallow submarine platform (WERNER et al., 2003), with a relatively mild slope into deeper water to the north, and steeper offshore slopes to the south and southwest (see Fig. 1).

The majority of the land in the Galapagos ( $97 \%$ ) is designated as a protected national park and all of the neighboring waters a marine preserve, and as such access to the shoreline is highly restricted. Aside from approximately 10 sandy beaches that are open to tourists, all other shoreline locations are strictly off limits to anyone without a research permit. All access to the shoreline is coordinated through the Galapagos National Park, and any landing requires a Park Ranger chaperone. While a few of the areas visited by the survey team were tourist sites, the majority were not. Understanding the time-sensitive nature of the tsunami reconnaissance work, and the realization that the tsunami had already altered the ecosystem, the Park permitted special research access to all of the Island's shoreline.

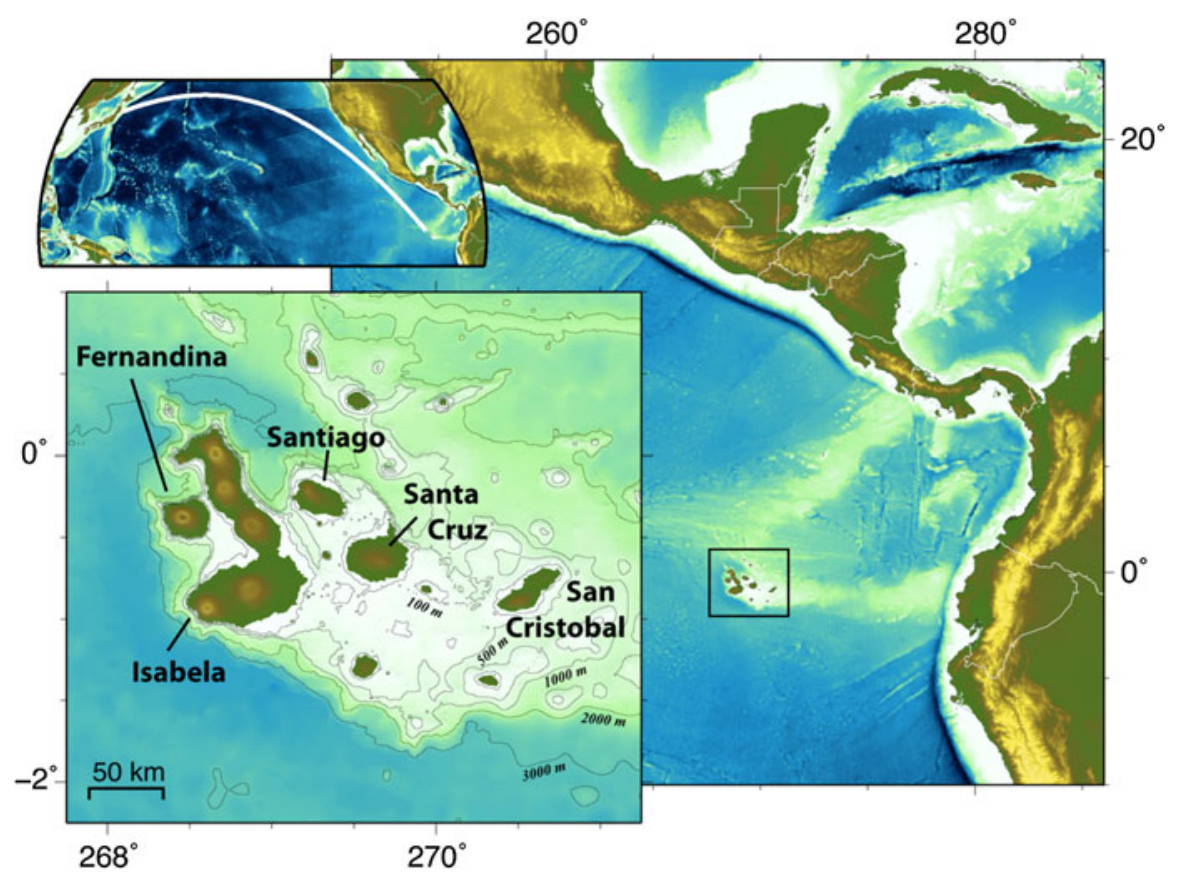

Figure 1

Location and bathymetry of the Galapagos Islands. In the upper left panel, the great circle path from the earthquake source region to the Galapagos is shown by the white line 

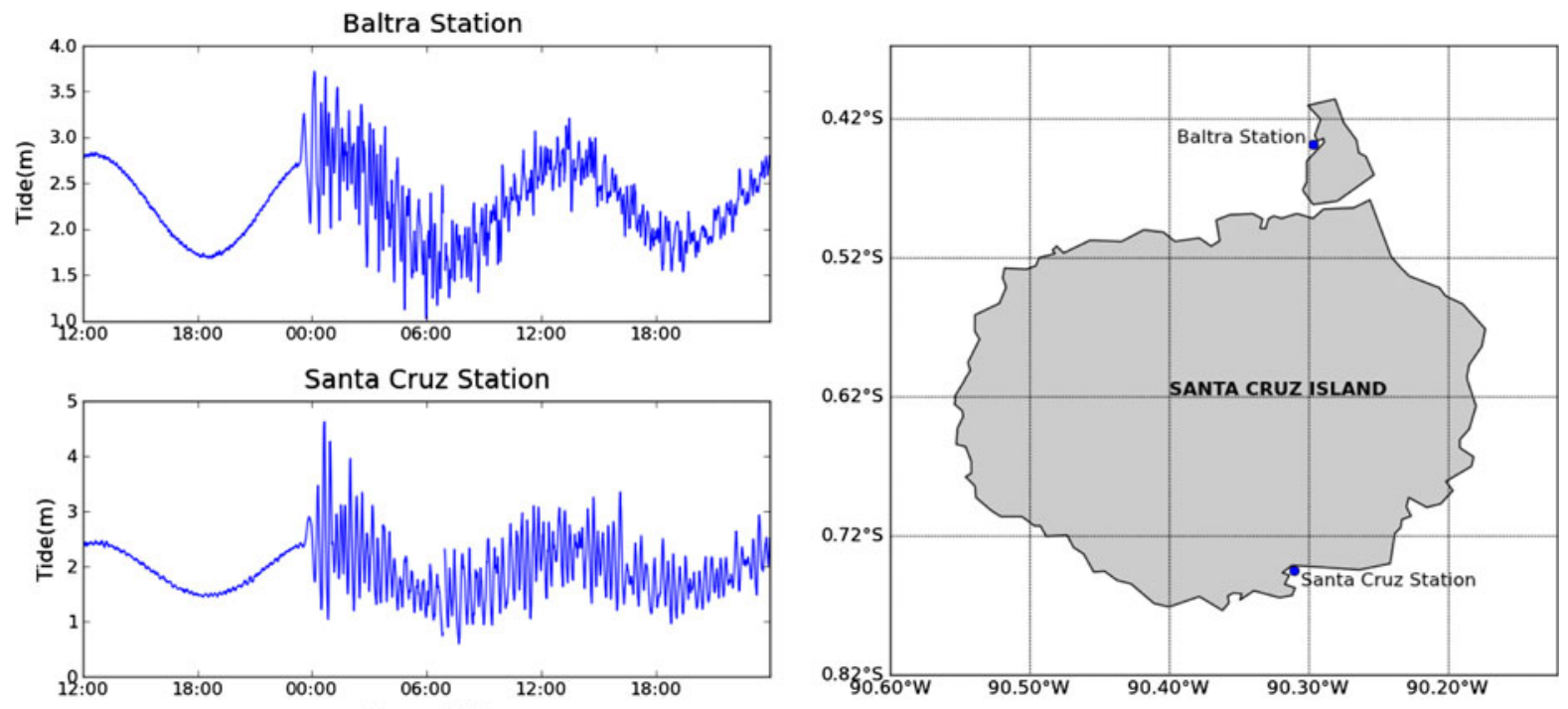

Figure 2

Tidal data from the Port Ayora and Balta stations, and a map of Santa Cruz showing the station locations

\section{Methodology}

The team assembled for this survey was experienced in tsunami reconnaissance and employed established techniques (DomineY-Howes et al., 2012; Synolakis and Okal 2005) for the survey. Tsunami flow markers, such as wrack lines, altered vegetation, broken tree branches, mud lines or sediment deposits were identified at each survey location. Eyewitness accounts of flow heights were also used when available. Tsunami height and inundation were measured using hand-held laser rangefinders to record vertical elevations and horizontal distances from the shoreline. Measured tsunami heights were corrected to reflect elevations relative to the sea level at the time of the tsunami. Wind wave action was low during the surveys and at the time of the tsunami, and it is assumed that wave setup is both small and similar between the different times. Co-author Morales performed a survey of southern Santa Cruz the day after the tsunami, while the other islands were visited in two separate surveys; the first less than 2 weeks after the tsunami, and the second 4 weeks later. In addition to the field data collected on the survey, instrumental data of the tsunami included two tidal stations and an Acoustic Doppler Current Profiler (ADCP), all situated around the inland of Santa Cruz (Fig. 2).
An immediate observation from examination of these tidal records is the timing of the first waves very near high tide. As will be discussed later, this timing significantly worsened the impacts of the tsunami.

Due to time constraints and a general inaccessibility of the coastline, the selection of candidate study sites was guided by numerical computations performed prior to the surveys. Numerical predictions were obtained using the COMCOT model (LiU et al., 1995). COMCOT solves the shallow water wave equations using a leap-frog numerical solution scheme and has the ability to use up to four layers of nested model grids. For the survey planning, we used a model with two grid levels. The primary grid covered the majority of the Pacific Ocean at $2 \mathrm{~min}$ resolution with a nested layer set over the Galapagos Islands using 30 arc-s resolution bathymetry data provided by INOCAR. To initialize the tsunami propagation model we used the US Geological Survey finite fault solution (USGS 2011). Figure 3 shows the computed maximum ocean surface elevations predicted by the model. Given the relatively coarse model resolution in this area (30 arc-s), the model predictions are not directly indicative of the tsunami runup. Accurate predictions of runup require detailed coastal bathymetry and topography (KANOGLU and Synolakis 1998) which was not readily 


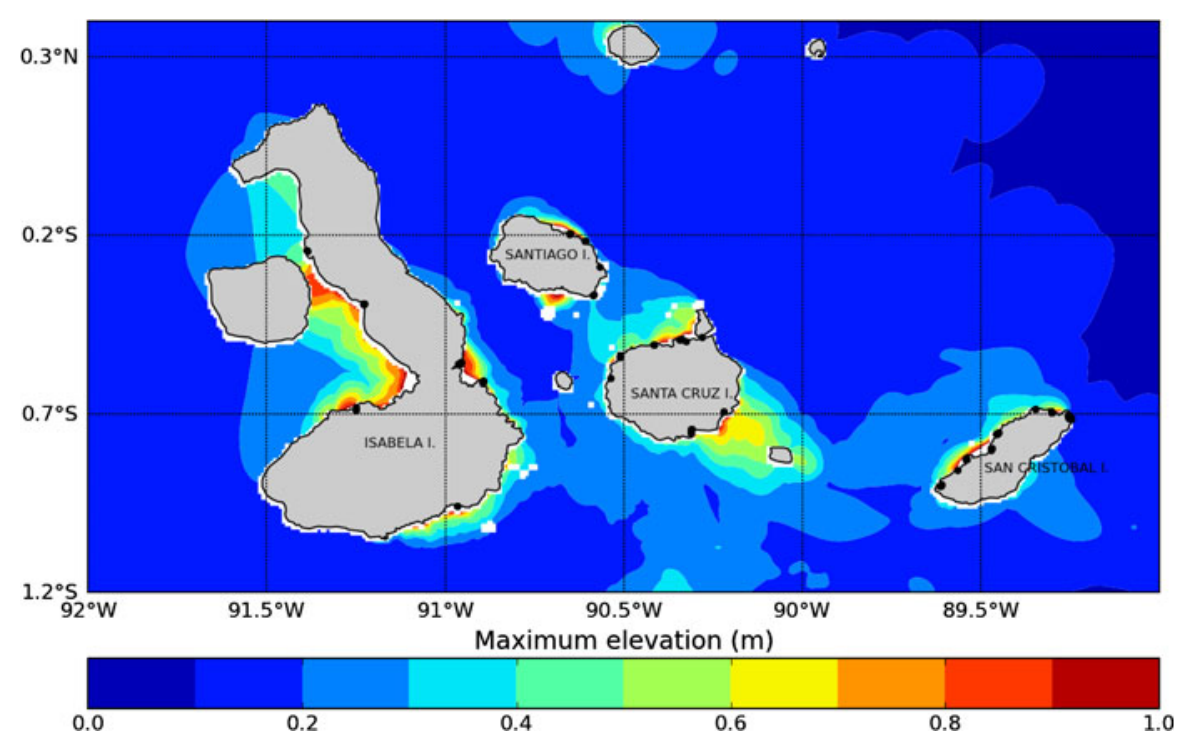

Figure 3

Main islands of the Galapagos, plotted with numerical simulation results. The black dots on the shorelines indicate survey locations

available. Thus the numerical predictions near the coastline are best interpreted as near-coast maximum tsunami amplitudes. To obtain tsunami runup, the offshore amplitude should be multiplied by some factor, (commonly between 0 and 5) that depends on the local bathymetry, topography and wave properties (LyNETT 2007). Nevertheless, the simulation results indicate areas of wave focusing and suggest stretches of coastline that may have been impacted by larger wave heights.

\section{Survey Results}

Field survey data is presented in tabular form in the Appendix. All elevation measurements presented in this paper have been corrected to a common tide level. For sites on San Cristobal, we used a tidal prediction based on the 'XTide' software package which provides harmonic predictions for Puerto Baquerizo Moreno on the west side of the island. For all other locations, tidal data from the Baltra station was used to correct measurements. Since there are no tidal stations on the islands of Santiago and Isabela; the approach of using a single station for multiple islands might introduce some error into the tidal correction due to spatial differences tidal elevations. However, the maximum difference between the Baltra tidal station and the San Cristobal predictions during the survey period is $7 \mathrm{~cm}$ suggesting that tide levels across the Islands are quite similar.

To correct the runup measurements made during the survey, the tidal elevation at the time of measurement must be referenced to some characteristic tidal level during the tsunami. Here, this characteristic tidal level is the tide elevation at the arrival of the highest tsunami crest. The timing of the highest tsunami waves was determined based on the Santa Cruz Islands tide gauge records (Baltra and Port Ayora). Based on these records, the largest wave was the third wave at Puerto Ayora (Santa Cruz station) which occurred at $0006 \mathrm{~h}$ UTC on 12 March [6:06 p.m. on 11 March Galapagos Local Time] and the second wave at the Baltra station at $0038 \mathrm{~h}$ UTC [6:38 p.m. on 11 March Galapagos Local Time] with initial tsunami arrival some 50 min earlier. The peak wave heights occurred within 20 min of the daily high tide. On that day, the predicted and observed maximum tidal levels at the two stations were within $1 \mathrm{~cm}$ of each other. Because the Baltra station is located approximately at the center of the island chain, we reference our measurements to this location and tsunami heights presented in this paper are given relative to high tide on the day of the tsunami. From this point forward, reported tsunami heights are relative to the tide level at the arrival of the maximum 

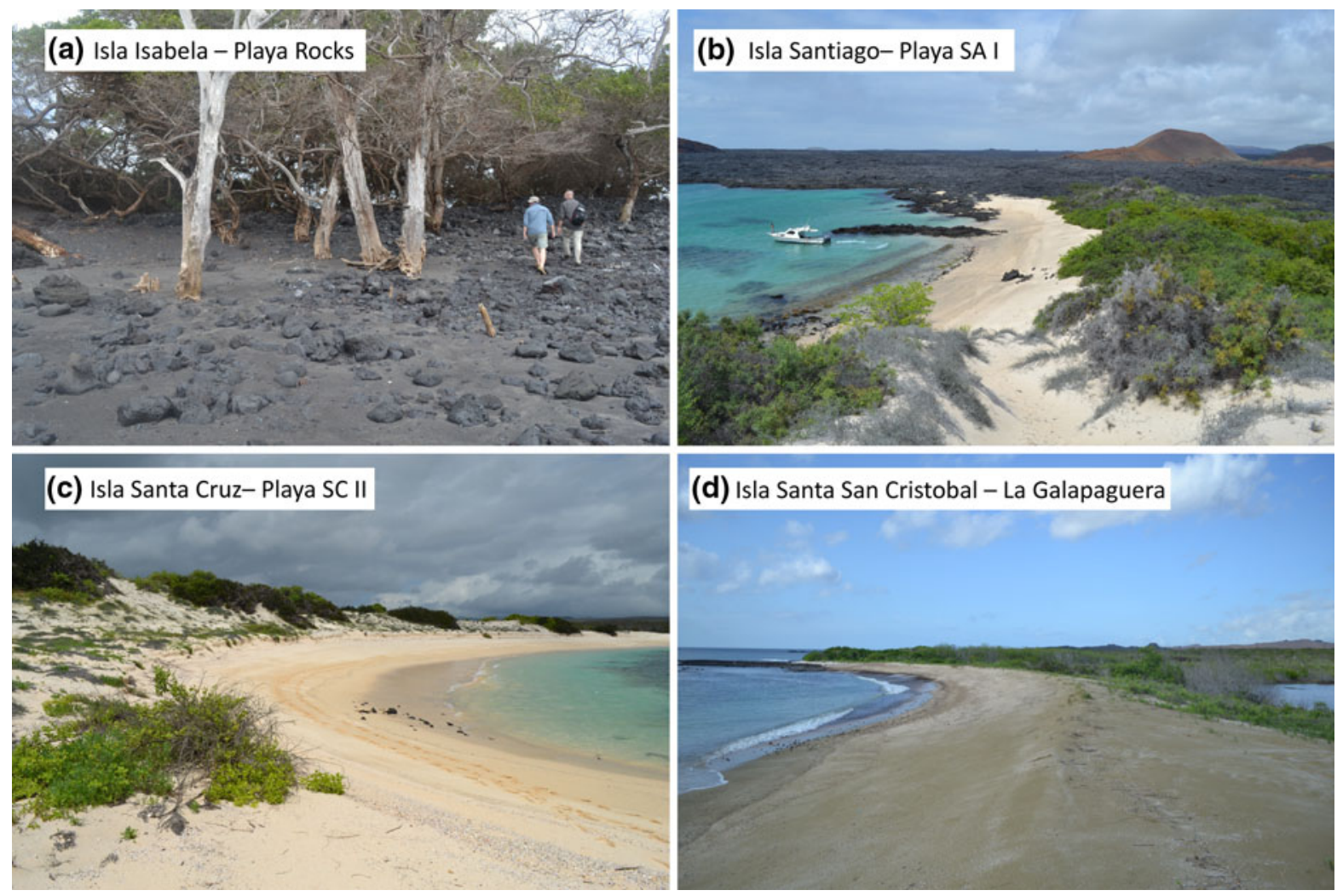

Figure 4

Photographs from the four main islands visited during the survey. In a is Playa Rocks, the location of the $6 \mathrm{~m}$ flow elevation marker, the highest elevation found during the survey; b shows a common coastal configuration on Santiago and Isabela, where a recent lava flow overruns a short, steep beach; $\mathbf{c}$ is a beach on the west side of Santa Cruz characterized by a high dune with the largest runup on this island; and $\mathbf{d}$ a typical beach-lagoon system found on San Cristobal, where the water visible on the right side of the image is the shallow lagoon

tsunami crest, equivalent to the high tide level on March 11th.

In the time between the tsunami and the second of the two field surveys, two large spring tide events occurred. In some locations, discerning between a tsunami wrack line and a spring tide wrack line was difficult. However, at a few locations, specifically where the tsunami was clearly larger than the spring tide elevation, the spring tide wrack lines could be inferred. Along beaches that were protected from large wind waves by, for example, a narrow entrance into a wider bay, the higher spring tide runup elevation was found to be $1.0 \mathrm{~m}$ above the high tide on March 11th. On open beaches, where wind wave action was not strongly restricted by nearshore obstructions, the higher spring tide runup elevation was found to be $2.0 \mathrm{~m}$ above the high tide on March 11 th. These values can be used to infer the relative magnitude of the tsunami as compared to regular tidal maxima. Any recorded flow marker or wrack line with tide-corrected elevation less than $2.0 \mathrm{~m}$ whose source was questioned during the survey has been removed from the dataset.

Survey results from the four main islands are presented in the following sections. To provide a visual context of the islands, a photograph from each of the islands is shown in Fig. 4. These photographs hint at the wide range of coastal configurations present in the Galapagos, from coarse rock beaches backed by abrupt lava-flow cliffs to wide sandy beaches connected to shallow lagoons.

\subsection{Isla Isabela}

Isabela is the largest of the islands yet only has the single settlement of Puerto Villamil on the southern 


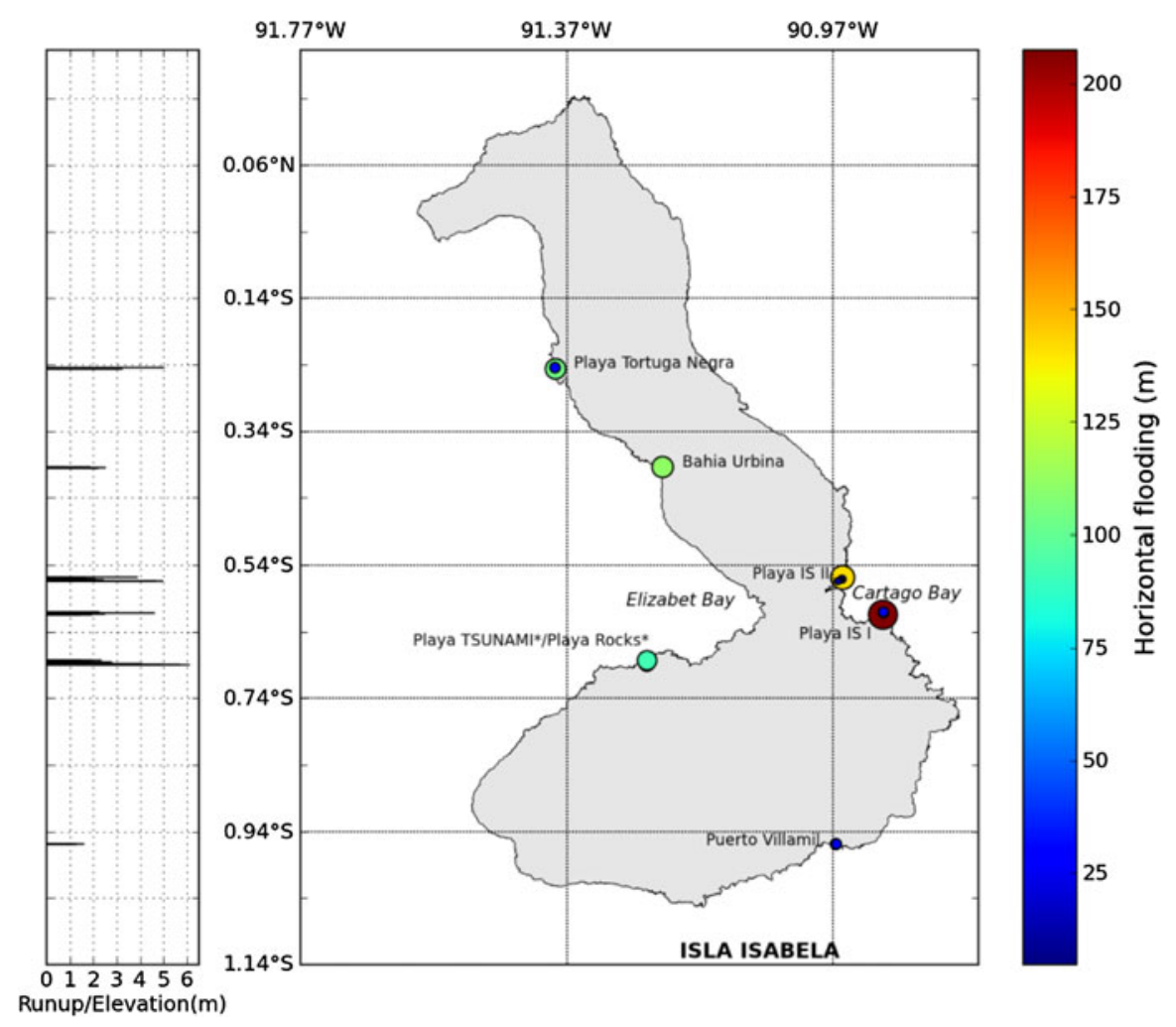

Figure 5

Survey results for the island of Isabela. The tsunami flow elevations are given on the left, and the colored circles indicate the inundation distances

shore. The island is extremely remote and rugged, with a few small sandy beaches tucked between steep lava rock sea cliffs and dense mangroves. Numerical simulations indicated that the largest tsunami heights should have occurred in the Bay of Carthage on the east and Elizabeth Bay on the west (Figs. 3, 5).

While the shorelines of Elizabeth Bay are wrapped in mangroves with no reasonable boat landing locations, the Bay of Carthage coast does have a few small sandy beaches where a landing was possible. Maximum flow elevations across the Bay of Carthage were consistently in the range of $4.5-5.0 \mathrm{~m}$. There was no beach dune in this area, as the short sandy beach connected directly to lava rock behind. The tsunami flow traveled over the natural channels in the lava rock reaching a maximum inundation distance of just over $200 \mathrm{~m}$ with a runup of $2 \mathrm{~m}$.

The survey team visited several locations along the west coast of Isabela, including Black Turtle Beach (Playa Tortuga Negra) to the north, Bahia Urbina just north of Elizabeth Bay, and Playa Rocks, a sandy beach south of Elizabeth Bay. The dune elevation at Black Turtle Beach was quite high, and the tsunami appeared to have overtopped it with just a few centimeters of flow depth, leaving behind a clear wrack line at an elevation of $5.0 \mathrm{~m}$. This is a very precise measurement of the maximum runup in the area. Urbina Bay is sheltered from wind waves by Fernandina Island, and was characterized by low dune crests of 1-2 $\mathrm{m}$ in elevation. The tsunami overtopped the dunes here and maximum flow elevation measured on the dune front face was $2.5 \mathrm{~m}$. The highest surveyed wave heights of $6.1 \mathrm{~m}$ were measured at the difficult to access Playa Rocks. This particular elevation likely represents a localized maximum, as immediately to the east and behind the beach was a $5 \mathrm{~m}$ high lava rock cliff which may have amplified the flow depth. A few hundred meters away from this site, maximum flow elevations were in the 3-4 m range, with inundation distances less than $90 \mathrm{~m}$.

In the town of Puerto Villamil the tsunami height was relatively small. However, eyewitness accounts 
by the staff of the Port Authority who were present at the time of tsunami were able to indicate the tsunami runup extents. The beaches in Puerto Villamil are wide and flat, a rather uncommon occurrence across the Islands. There was no inundation in the town due to the tsunami, and the water did not completely traverse the wide beach. Runup measurements were consistent, and found to be approximately $1.5 \mathrm{~m}$. Residents noted that this elevation was in fact less than the combined spring tide and wave setup that occurred in the week following the tsunami.

\subsection{Isla Santiago}

Santiago Island (Fig. 6) is made of two volcanoes and covers an area of roughly $600 \mathrm{~km}^{2}$. The island has a number of sandy beaches open to tourists located on the east and west side of the island. The south side of the island has virtually no sandy beaches as rough, black lava rock fronts most of the southern shoreline. The northern coast is also largely rocky; however there are a handful of sandy beaches with safe landing access for small boats. The numerical model results suggest that the largest tsunami wave heights were expected along the northern coast and along a small stretch of the southern coast, areas where shallow coastal waters extend relatively far offshore (Fig. 3). It was not possible to visit the southern section of Santiago, and therefore it is not known whether the modeled height patterns are reasonable in this area.

We first stopped at Sombrero Chino, a small islet on the southeast coast. The islet is so named because of a steep central peak surrounded by low, mildly sloping lava plains and is visually similar to a Chinese-style hat. The beaches here were quite narrow, with less than $15 \mathrm{~m}$ of sandy beach backed by rough lava terrain and vegetation consisting of low grasses and shrubs. There were no clear signs of tsunami inundation in this area; three clear wrack lines were noted, but each was at an elevation lower than the spring tide threshold. At this location, all that can be said with confidence is that the maximum tsunami elevation was less than $2.0 \mathrm{~m}$. On the east side of Santiago, the situation was similar. At an un-named sandy beach (Playa SA I in Fig. 6), wrack lines were found at elevations below the dune crest, and more importantly below the turtle nests, a clear sign that the tsunami did not exceed the high tide level. This was confirmed by the survey data and therefore we can only say that maximum tsunami height was less than $2.0 \mathrm{~m}$ here. We note that both of these findings are consistent with the model predictions.

On the north coast of Santiago we surveyed two sites. The first was a small cove beach protected by a rocky barrier (Playa SA II in Fig. 6). The open entrance to the cove was $25 \mathrm{~m}$ wide, while the width of the enclosed cove was approximately $130 \mathrm{~m}$. The

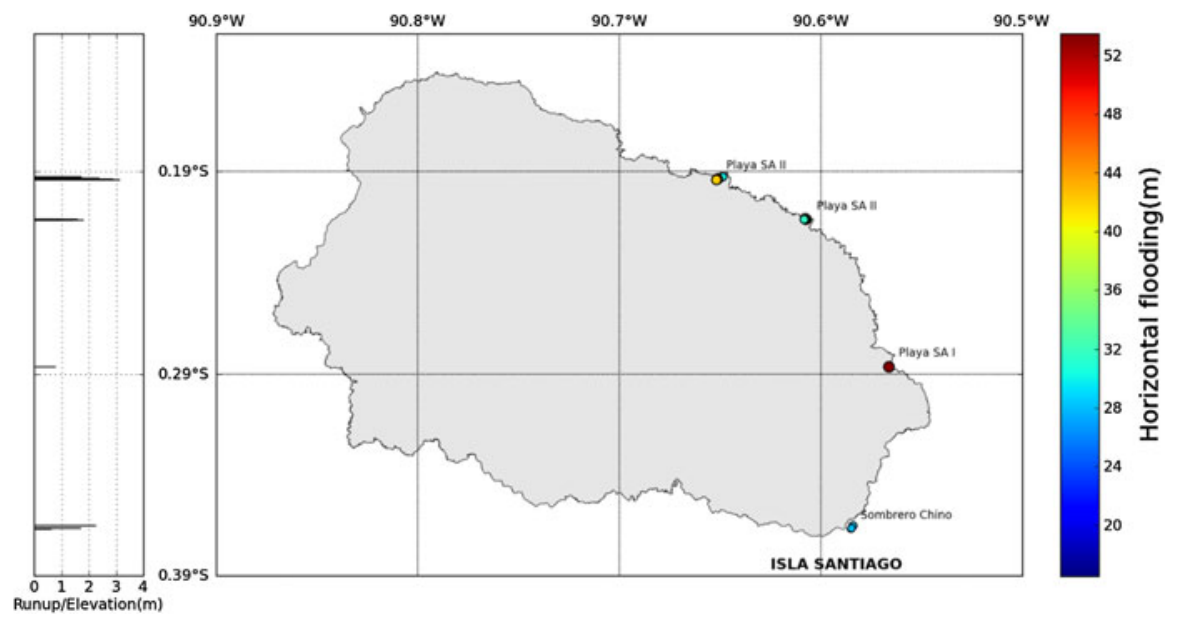

Figure 6

Survey results for the island of Santiago. The tsunami flow elevations are given on the left, and the colored circles indicate the inundation distances 
cove entrance was aligned with the centerline of a symmetrically curved sandy beach. This beach was protected from wind waves and we measured a high tide wrack line at $+1.0 \mathrm{~m}$. The tsunami overtopped the dune everywhere along this beach creating thin sand fans extending to $20 \mathrm{~m}$ beyond the dune crest. Maximum flow elevations of 1.6 and $1.8 \mathrm{~m}$ were inferred through flow markers in vegetation on the backside of the dune, with maximum flow depths of $50 \mathrm{~cm}$. There was no clear evidence of significant lateral variation of tsunami elevation here, likely due to the small spatial scale of the enclosed beach relative to the tsunami wavelength.

Traveling to the west, the survey team arrived at the last survey site on Santiago, a $200 \mathrm{~m}$ long sandy beach bounded by rocky outcroppings. The beach is completely exposed to incoming wind waves, and faces to the north-northwest, similar to the direction of tsunami approach. Again, the dune system along this beach was overtopped across its entire length. The highest dune elevation of $2.9 \mathrm{~m}$ was overtopped by a flow depth of $30 \mathrm{~cm}$ making a maximum tsunami height of $3.2 \mathrm{~m}$. This beach appeared to be a particularly popular nesting site for sea turtles, with most of the dune crest re-worked and altered by turtle activity. Since this beach is restricted for both recreation and research, there are no pre-tsunami observations of the beach, and it is not known what impacts the tsunami may have had on existing turtle nests, which would have been flooded during the event.

\subsection{Santa Cruz}

Santa Cruz is home to Puerto Ayora, the largest town in the Galapagos and the location of INOCAR headquarters (Fig. 6). Puerto Ayora was by far the most impacted location in the Galapagos Islands; many beachfront hotels and harbor structures experienced significant flooding and damage. Figure 7 provides a number of photographs from the southern coastline taken immediately after the event, indicating the extent of the damage. Several small boats left in the harbor had broken free from their moorings and washed up on the beach. Tsunami wave loads caused the collapse of a few shorefront structures. Damage was typical of tsunami impact with widespread observations of blown out windows and doors. Flow elevations and runup varied from 2.0 to $2.8 \mathrm{~m}$ throughout the city, with the largest elevations found at INOCAR headquarters, where buildings are situated just tens of meters from the water.

A few kilometers away at Punta Estrada, tsunami heights were similar to those in Puerto Ayora, with maximum flow elevations from 2.0 to $2.4 \mathrm{~m}$, and flow depths of $\sim 1 \mathrm{~m}$. Small structures, such as rock and mortar walls and wooden boardwalks were destroyed. At Playa Garrapatero, on the southern coastline, maximum flow elevations were $3.3 \mathrm{~m}$. This location has a short sandy beach, and is one of the few public access beaches in the Islands that does not require boat access. Additionally, a Park Ranger is on duty at all times, and was able to provide a complete account of the tsunami effects. The most remarkable observation was a breach $29 \mathrm{~m}$ wide in the single dune lining the beach. Much of the sand from the breach had been washed into a lagoon $115 \mathrm{~m}$ from the shoreline, and numerous sea turtle nests built into the dune were destroyed. This particular beach and lagoon system is a promising location to search for prehistoric tsunamiites (SHIKI et al., 2008); indeed, a recent investigation (Arcos et al., 2012), has discovered a 1000 year old candidate deposit here.

We surveyed six sites on the north side of Santa Cruz. Starting in the west, at a small pocket beach, it was impossible to differentiate between the tsunami and high-tide debris lines, implying tsunami heights of $2 \mathrm{~m}$ or less. However, just $10 \mathrm{~km}$ north along the coast, where shallow bathymetry extends offshore, we measured the largest tsunami heights on Santa Cruz. The relatively high dunes on this beach, with crest elevations up to $4.5 \mathrm{~m}$, were uniformly overtopped by a maximum tsunami height of $4.7 \mathrm{~m}$. Towards the Canal de Itabaca, a narrow waterway separating Santa Cruz from the small island of Baltra, tsunami heights diminished to less than $2 \mathrm{~m}$, but were associated with a large increase in current speed through the channel due to the topographical constriction. This feature will be discussed in detail in Sect. 5 below Fig. 8.

\subsection{Isla San Cristobal}

San Cristobal Island (Fig. 9) is relatively long and narrow extending northeast to southwest. 

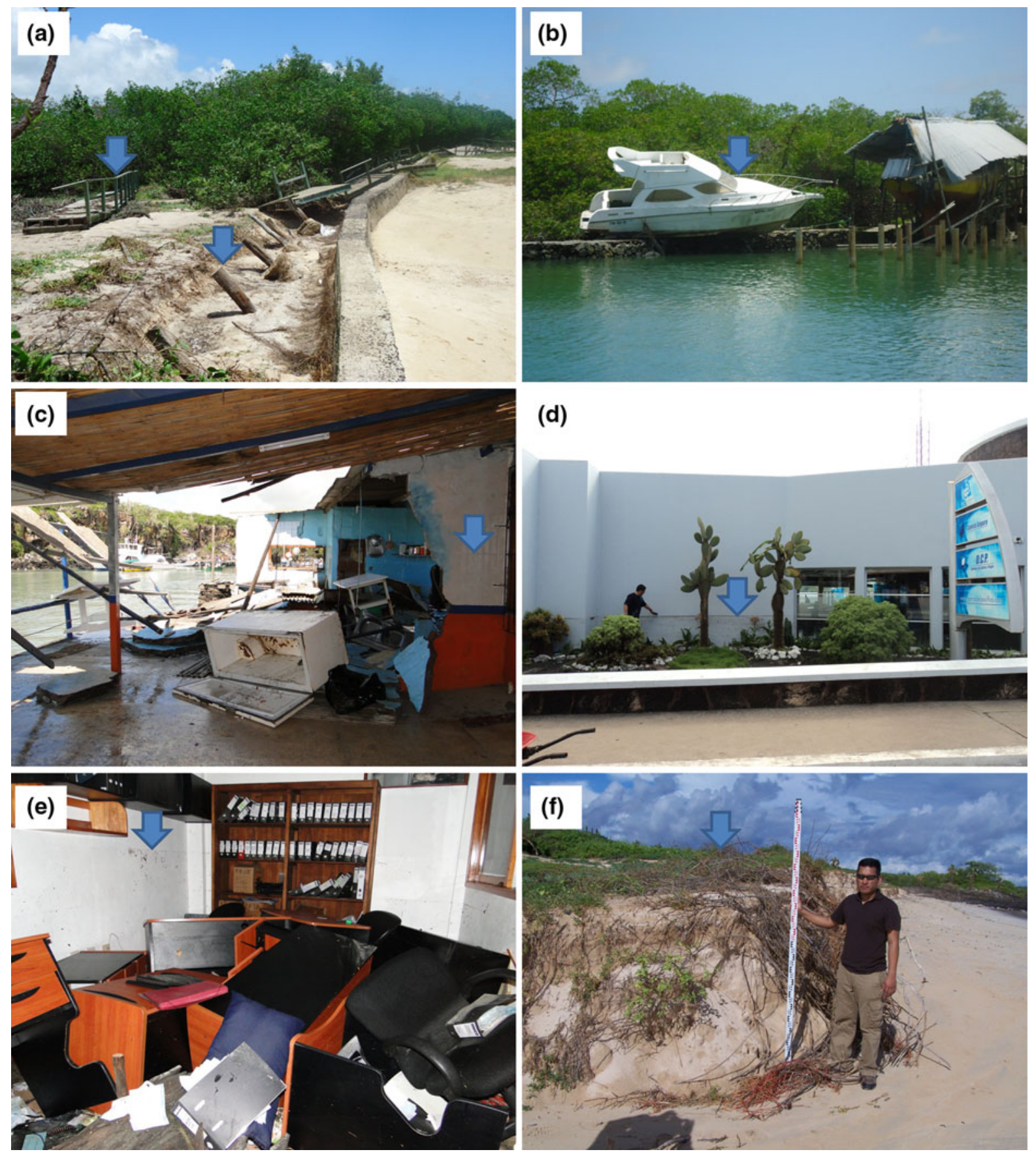

Figure 7

Photographs of damage along the southern coastline of Santa Cruz. In a a boardwalk destroyed by the tsunami in Punta Estrado, where the arrows show the displaced boardwalk module and the bent piles that originally supported the walkway; b a grounded boat in Punta Estrado resting on a dock; c structural damage to a building near the water in Puerto Ayora, where the arrow shows the maximum flow elevation at this site; $\mathbf{d}$ and e a bank and hotel in Puerto Ayora with arrows indicating mudlines on the walls; and $\mathbf{f}$ dune breach scarp at Playa Garrapatero, 


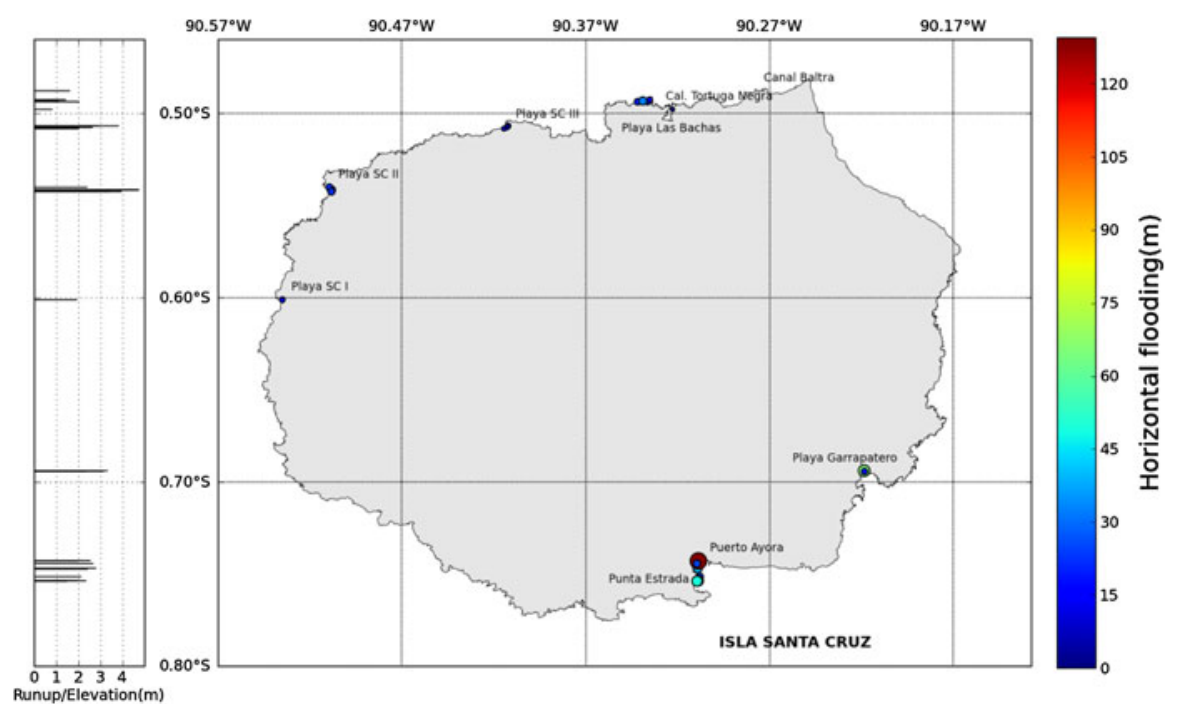

Figure 8

Survey results for the island of Santa Cruz. The tsunami flow elevations are given on the left, and the colored circles indicate the inundation distances. Note that the measurement given as "Canal Baltra" is the harbor on the Santa Cruz side of the Canal de Itabaca

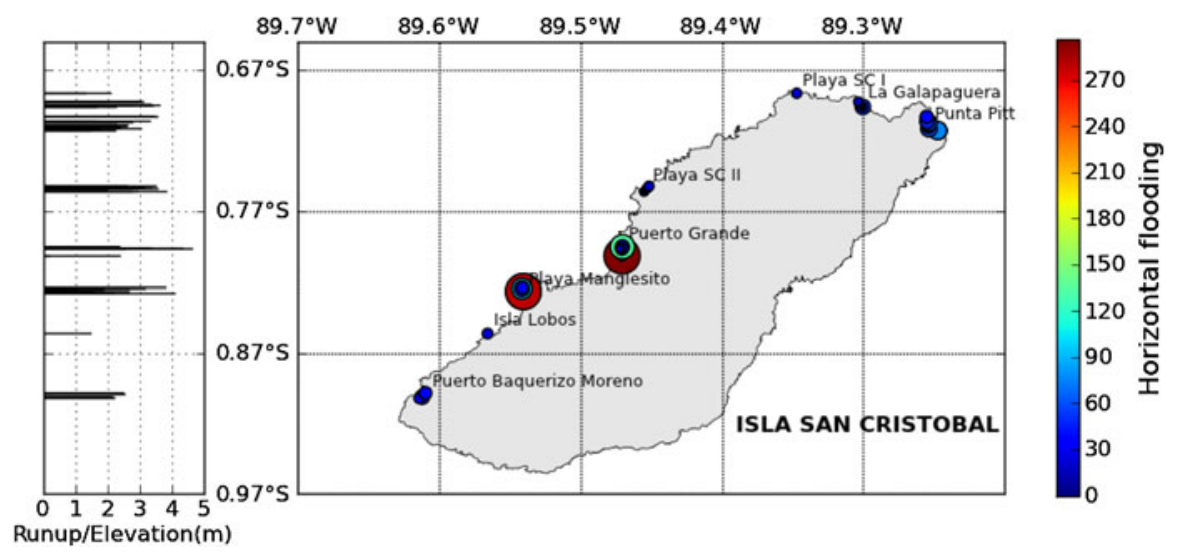

Figure 9

Survey results for the island of San Cristobal. The tsunami flow elevations are given on the left, and the colored circles indicate the inundation distances

The main town of Puerto Baquerizo Moreno, the capital of the Galapagos Islands, is situated on the southwestern tip of the island. With San Cristobal's location to the southeast of the Island group, one might expect the northern coastline to be sheltered from significant tsunami effects due to shadowing from the islands to the west and north. Likewise, it would be expected that the tsunami might approach from the south, strongly affecting that side of the island. However, as indicated from the numerical model results and confirmed during the survey, this was not the case.
Inspection of the bathymetry around the Galapagos shows a basin to the north of Fernandina and Santa Cruz Islands with a depth of more than $3,000 \mathrm{~m}$ and oriented roughly parallel to the $135^{\circ}$ great circle path which runs unobstructed from the tsunami source region to the Galapagos (Fig. 1). This feature, combined with refractive focusing to the north San Cristobal, allowed tsunami energy to be concentrated on the north coast of San Cristobal. Furthermore, the shelf break running from the western extent of Isabela towards the southeast is oriented parallel to the tsunami approach azimuth and prevented significant 
wave energy from being refracted towards the southern shore of San Cristobal.

We surveyed eight different sites on the north coast of San Cristobal, each requiring access by boat. As shown in Fig. 9, the coverage across the north coast is complete, from Punta Pitt in the east to Puerto Baquerizo Moreno in the west. With the exception of the developed Puerto Baquerizo area, the sites can be broadly described as steep, sandy beaches featuring a single, small dune with a crest elevation between 2.0 and $3.5 \mathrm{~m}$ above the water level at the time of tsunami. In all locations, the dune crest was at least partly overtopped by the tsunami, making a direct runup measurement possible. In Playa Manglecito, the tsunami waves scoured an $\sim 80 \mathrm{~m}$ long breach in the dune with a scarp height of $1.6 \mathrm{~m}$ on either side. Large sand deposits were observed a lagoon situated behind this particular dune, however the lagoon itself was not accessible by the survey team. Runup and tsunami heights along the dune crest were consistent among the sandy beach sites, with elevations typically in the range of 3.5-4.0 m. The largest tsunami height of $4.7 \mathrm{~m}$ was measured on a rocky outcrop at Puerto Grande, located approximately in the middle of San Cristobal's north coast. At most sites, inundation distances were not well defined due to lagoons located immediately behind (within $50 \mathrm{~m}$ ) of the dune crest. The situation was different however, on the beaches of Playa Manglecito and Puerto Grande, where the topography was characterized by steep, narrow and winding lava channels that funneled the tsunami surges up to $300 \mathrm{~m}$ inland carrying marine life, such as small sharks, fish, and sea turtles with it.

Puerto Baquerizo Moreno is a small harbor town that is also home to the Navy base of the Galapagos, and numerous eyewitness accounts were given by officers and conscripts. Minimal flooding was observed and there was only minor overtopping of the $2.0-2.5 \mathrm{~m}$ high sea wall that fronts the town. Runup and flow heights ranged from 2.2 to $2.6 \mathrm{~m}$, with a maximum inundation distance of $46 \mathrm{~m}$.

\section{Tsunami Currents}

Strong currents were noted in all of the main harbors and in particular in the Canal de Itabaca, a narrow waterway separating the islands of Santa Cruz and the small island of Baltra. The channel is approximately $4.5 \mathrm{~km}$ in length, with a maximum width of $1.2 \mathrm{~km}$ and a minimum width of $330 \mathrm{~m}$. Eight navigational and sensor buoys anchored in the channel were transported by the tsunami currents with the largest displacement of $810 \mathrm{~m}$, and an average displacement of $290 \mathrm{~m}$ (Fig. 10). The navigational buoys are made of steel and aluminum, and weigh approximately 1.5 tons with an anchoring system consisting of a metal chain connected to a 4 ton concrete mooring block. The seafloor in this area is rocky and relatively level, with roughness due predominately to the relief of individual boulders sitting on the bottom. While the pre and post-tsunami positions of several buoys are known, buoy positions during the tsunami were not recorded and thus motion time series and/or velocities are unknown. While there is a great amount of uncertainty in the precise conditions under which the moorings started to move, it is possible to make a rough estimate of the current speed necessary to do so. Using high Reynolds number drag coefficients for the buoy, chain, and anchor, with an assumption of a log-law velocity profile over an even bottom, the required surface current is estimated at $1.5 \mathrm{~m} / \mathrm{s}$. The majority of the horizontal force transferred to the anchor comes from the drag on the surface buoy.

Numerical simulation of the currents in the Canal de Itabaca should be a much better predictor of flow speed compared to the rough calculations above, and provides spatial variability of the flow as well. For this simulation, the model of Son et al. (2011) is used. This model uses varying nested layers of model grids with different theoretical assumptions. Here, a Boussinesq model (e.g. KIM and LynetT 2011) is nested over the Canal de Itabaca and embedded into a system of COMCOT grids covering the entire Pacific Basin. The Boussinesq model is preferred for this application as it is known that when estimating currents induced by a tsunami, this model should provide a physically appropriate result (LyNETT et al., 2012). For these computations, we used the same USGS finite fault model used for the pre-survey planning simulations (Fig. 3). The spatial resolution of the Boussinesq model is $1 / 3$ arc-second (approx. $10 \mathrm{~m}$ ), derived 

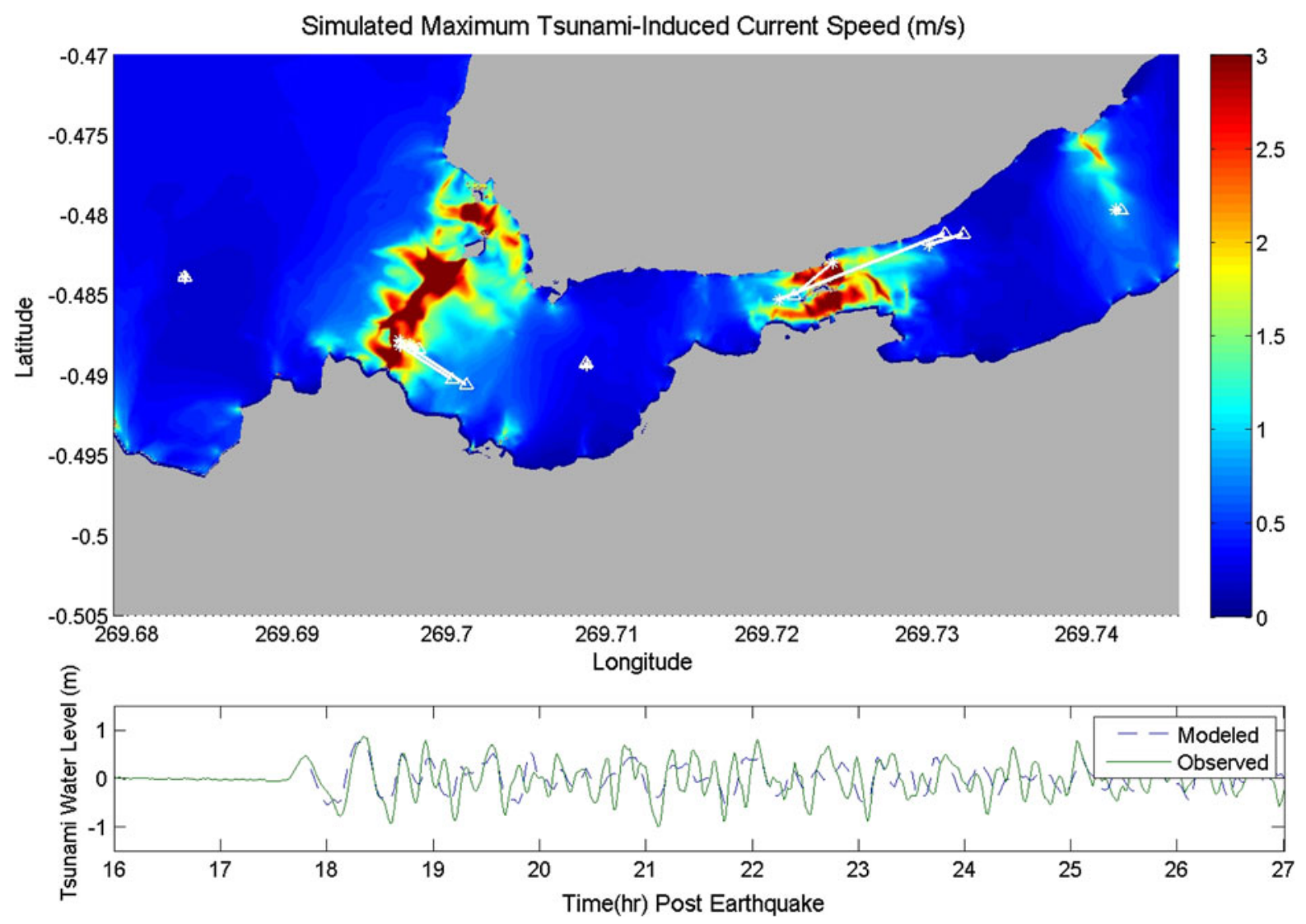

Figure 10

Simulated currents through the Canal de Itabaca. In the top plot, the white lines show the before (star) and after (triangle) locations of the displaced buoys, overlaid on the maximum currents predicted by the simulation. In the lower plot is the comparison of the tsunami-induced water level changes between the simulation and the Baltra tidal station, located at $0.43333 \mathrm{~S}, 90.28333 \mathrm{~W}(269.7167 \mathrm{E})$

from high-resolution bathymetry provided by INOCAR.

Figure 10 shows the maximum predicted current speeds in the Canal de Itabaca and a comparison between modeled and measured water level data from the nearby Baltra tide gauge. Modeled water levels match measured data reasonably well for the first few hours of the simulation; however the model generally under predicts measured amplitudes. The strongest currents are concentrated at the west and east ends of the channel, where the water depth becomes locally shallower. In these regions, the maximum predicted flow speeds are between 3 and $4 \mathrm{~m} / \mathrm{s}$. There is a clear correlation between the simulated regions of high velocity and the displaced buoys; in locations where the predicted currents are less than $1 \mathrm{~m} / \mathrm{s}$, the buoys were not moved significantly. In general the modeling results provide an excellent indicator of where the largest currents in the channel should be expected in tsunami events.

In the harbors of the Galapagos, moderate currents were observed over an extended period. In Puerto Villamil on the island of Isabela, a small fishing vessel was pulled from its mooring and drifted in the harbor until the local Navy was able to re-secure it. In Puerto Ayora, numerous ships broke their moorings, but the evacuation of the town limited any observations of how and when this occurred. However, eyewitness accounts estimate localized current speeds in excess of 5 knots in Puerto Ayora in a flow constriction in the back of the harbor in the early morning hours of March 12th (local time). Additionally in Puerto Ayora, a current meter (ADCP) was installed and in operation during the tsunami. The ADCP was located in the center of the bay, away from the tide gage which is located closer to shore 

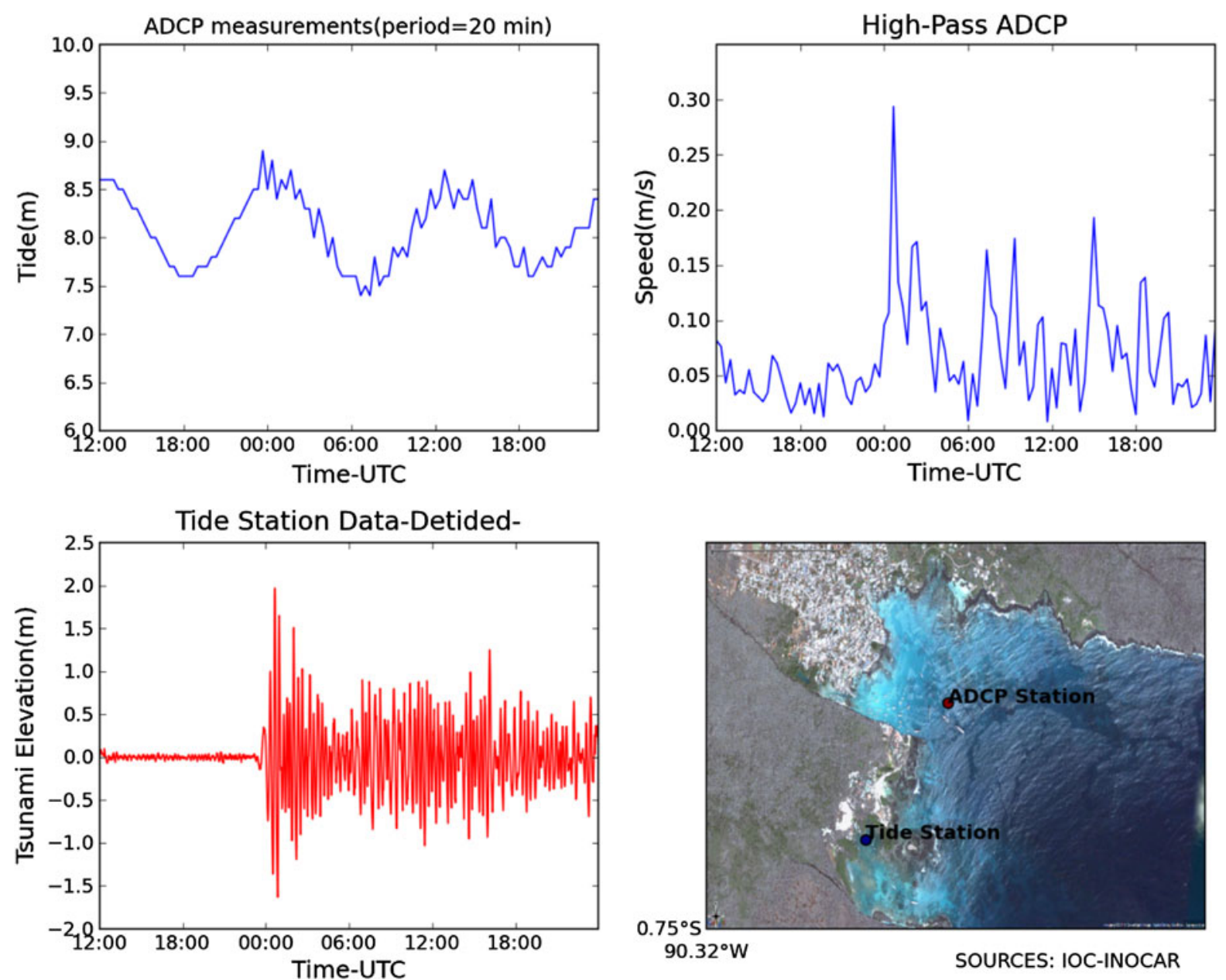

Figure 11

ADCP data measured during the tsunami in Port Ayora. The map inset shows the precise location of the device

(Fig. 11). The sampling rate of the data is $20 \mathrm{~min}$, and can therefore only provide snapshots, rather than a detailed time history of the currents during the tsunami. Strong currents persisted for more than $24 \mathrm{~h}$ after tsunami arrival. Indeed, current speeds $16 \mathrm{~h}$ after tsunami arrival are similar in magnitude to those in the first few waves. In general, the maximum measured tsunami-induced currents are $0.3 \mathrm{~m} / \mathrm{s}$, or about 0.6 knots. Note again, however, that the long sampling rate and associated averaging is likely to underestimate the true peak current speeds.

Numerical simulation of the currents in Port Ayora is performed using the same model as described for Canal de Itabaca above (Fig. 12). The maximum currents predicted in the harbor are between 1.0 and $1.5 \mathrm{~m} / \mathrm{s}$ in the open waters with predicted overland flow speeds in excess of $2.0 \mathrm{~m} / \mathrm{s}$. A direct comparison between the model and measurements does not exhibit a good fit between the two. While the numerical simulation approximately captures the magnitude and timing of the first velocity peak, the agreement between model and simulation after this time is not good with the model over predicting the measured current speeds. There are many potential causes for the mis-fit, however due to the coarse temporal resolution of the ADCP data, these causes are difficult to identify. One of the more important conclusions of this comparison is the necessity of higher resolution current data during tsunami events. Examination of the 2-min and 20-min numerical data suggests that the 20 min sampling rate does not provide a useful representation of the maximum or minimum flow speeds. To properly record the complex current variations in very 

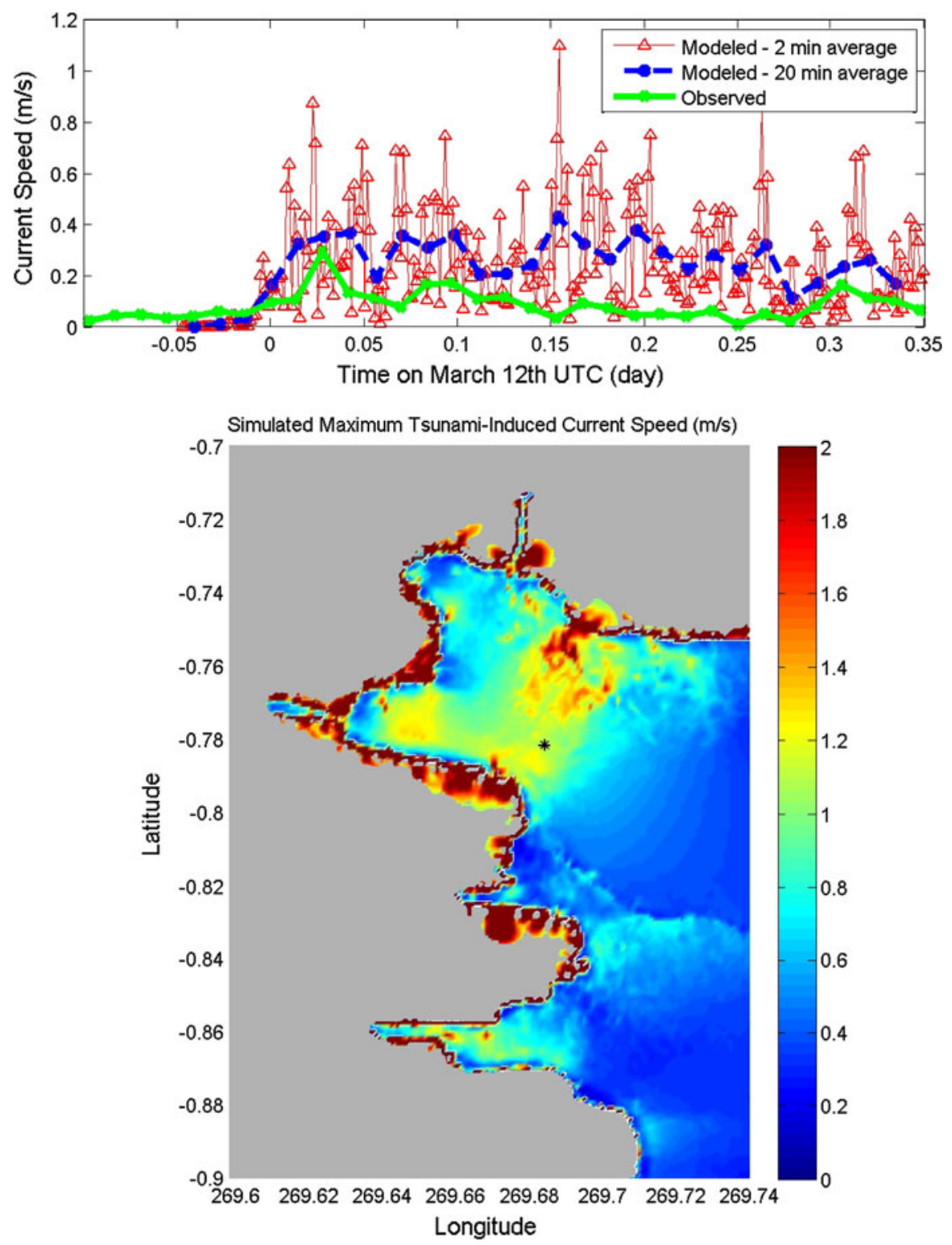

Figure 12

Simulated currents in Port Ayora. In the bottom plot, the black star shows the location of the ADCP, overlaid on the maximum currents predicted by the simulation. In the top plot is the comparison of the tsunami-induced flow speeds between the simulation and the ADCP, with numerical predictions using 20-min averaging (similar to the ADCP) and 2-min averaging

shallow water, current measurement devices should sample at intervals of a few minutes or less.

\section{Conclusions}

The post-tsunami reconnaissance of the Galapagos Islands included three separate surveys which took place in the days and weeks immediately after the tsunami. The extended nature of this effort was due largely to the inaccessibility of the coastline in the Island chain, and the required permissions needed to land on these beaches. The population of the Islands is small and concentrated in a few harbor towns, all of which experienced the tsunami and were impacted to varying degrees. In Puerto Ayora, structures were 
damaged and flooding of the town was extensive, while in Puerto Villamil the tsunami did not cross the wide beach and no flooding was observed. The largest tsunami heights were observed along the remote beaches away from populated areas and maximum tsunami heights on each island ranged from 4 to $6 \mathrm{~m}$. Sandy beaches tended to be localized features, relatively short alongshore and tucked between steep lava cliffs. Many of the beaches we studied consisted of a single dune backed by a lagoon. These dunes are used as nesting sites for sea turtles, and on the dunes that were overtopped and eroded by the tsunami, turtle nests were flooded or washed away.

This survey is the first ever comprehensive account of a tsunami in the Galapagos Islands, and suggests that impacts can be severe, yet highly variable in the island chain. The effect of the largest tsunami waves, which occurred around the time of high tide, would best be described as a minor to moderately severe. Of more pressing future concern to the Islands would be preparing for a much larger local event similar to the $19068.8 \mathrm{Mw}$ earthquake off the Ecuadorian coastline (Kanamori and McNally 1982). This earthquake is known to have generated a Pacific-wide tsunami including a $3.6 \mathrm{~m}$ wave in Hilo (AвE 1979); however there are no records of the wave in the Islands, as they were not inhabited at this time. The dune-lagoon systems on the islands may provide opportunities for sedimentological dating of previous tsunamis, and numerical studies should be initiated to estimate heights and inundation distances in both the populated coastal areas and the numerous remote tourist beaches.

\section{Acknowledgments}

The authors wish to thank the Galapagos National Park for facilitating rapid access to typically restricted beaches. In particular, we thank the Park rangers Carlos Ortega, Jose Caizabanda, and Rene Freire for accompanying us on our surveys. Coordination through INOCAR was indispensable, and the survey would not have been possible without their help. The authors thank co-editor of this volume Jose Borrero for his extensive assistance in revising this manuscript, including the creation of the maps in Fig. 1 using the GMT plotting software (WESSEL and SMITH 1991). Funding for the effort was provided by a National Science Foundation RAPID grant\# 1136534 to Weiss and Lynett.

\section{Appendix}

See Table 1

Table 1

Complete table of survey data

\begin{tabular}{lllll}
\hline Location & Island & Coordinates & Flow/runup elevation (m) & Inland distance (m) \\
\hline El Garrapatero & Santa Cruz & S0 41.632 W90 13.262 & 3.34 & 64.7 \\
El Garrapatero & Santa Cruz & S0 41.656 W90 13.253 & 2.35 & 18 \\
El Garrapatero & Santa Cruz & S0 41.652 W90 13.236 & 3.15 & 0 \\
Punta Estrada & Santa Cruz & S0 45.081 W90 18.629 & 2.14 & 25.4 \\
Punta Estrada & Santa Cruz & S0 45.209 W90 18.684 & 1.98 & 0 \\
Punta Estrada & Santa Cruz & S0 45.215 W90 18.685 & 2.36 & 55.1 \\
Punta Estrada & Santa Cruz & S0 45.228 W90 18.716 & 1.5 & 50 \\
Black Turtle Cove & Santa Cruz & S0 29.869 W90 19.517 & 0.83 & 8 \\
Las Bachas & Santa Cruz & S0 29.618 W90 20.328 & 2.02 & 20 \\
Las Bachas & Santa Cruz & S0 29.557 W90 20.263 & 1.44 & 15 \\
Las Bachas & Santa Cruz & S0 29.621 W90 20.652 & 2.05 & 21 \\
Las Bachas & Santa Cruz & S0 29.594 W90 20.483 & 1.12 & 32 \\
Baltra Channel & Santa Cruz & S0 29.266 W90 16.824 & 1.63 & 0 \\
Puerto Ayora & Santa Cruz & S0 44.807 W90 18.696 & 2.81 & 40 \\
Puerto Ayora & Santa Cruz & S0 44.834 W90 18.756 & 2.44 & 0 \\
Puerto Ayora & Santa Cruz & S0 44.561 W90 18.589 & 2.56 & 23.4 \\
Puerto Ayora & Santa Cruz & S0 44.571 W90 18.672 & 2.01 & 129.5 \\
\hline
\end{tabular}


Table 1 continued

\begin{tabular}{|c|c|c|c|c|}
\hline Location & Island & Coordinates & Flow/runup elevation (m) & Inland distance $(\mathrm{m})$ \\
\hline Puerto Ayora & Santa Cruz & S0 44.657 W90 18.723 & 2.69 & 25 \\
\hline Puerto Grande & San Cristobal & S0 48.121 W89 28.227 & 2.41 & 296.2 \\
\hline Puerto Grande & San Cristobal & S0 48.121 W89 28.227 & 0.21 & 20.9 \\
\hline Puerto Grande & San Cristobal & S0 47.797 W89 28.219 & 2.98 & 18.4 \\
\hline Puerto Grande & San Cristobal & S0 47.734 W89 28.211 & 2.4 & 135 \\
\hline Puerto Grande & San Cristobal & S0 47.734 W89 28.211 & 1.4 & 45 \\
\hline Puerto Grande & San Cristobal & S0 47.788 W89 28.216 & 3.38 & 18.4 \\
\hline Puerto Grande & San Cristobal & S0 47.815 W89 28.234 & 4.37 & 35 \\
\hline Puerto Grande & San Cristobal & S0 47.815 W89 28.234 & 1.67 & 35 \\
\hline Puerto Grande & San Cristobal & S0 47.837 W89 28.280 & 2.57 & 18 \\
\hline Puerto Grande & San Cristobal & S0 47.820 W89 28.315 & 4.66 & 13 \\
\hline Playa Manglesito & San Cristobal & S0 49.564 W89 32.462 & 0.66 & 87 \\
\hline Playa Manglesito & San Cristobal & S0 49.564 W89 32.462 & 1.9 & 24 \\
\hline Playa Manglesito & San Cristobal & S0 49.637 W89 32.482 & 1.5 & 87 \\
\hline Playa Manglesito & San Cristobal & S0 49.637 W89 32.482 & 1.6 & 26 \\
\hline Playa Manglesito & San Cristobal & S0 49.689 W89 32.484 & 4.12 & 25 \\
\hline Playa Manglesito & San Cristobal & S0 49.689 W89 32.484 & 2.22 & 25 \\
\hline Playa Manglesito & San Cristobal & S0 49.618 W89 32.416 & 1.39 & 281.7 \\
\hline Playa Manglesito & San Cristobal & S0 49.618 W89 32.416 & 2.69 & 65 \\
\hline Playa Manglesito & San Cristobal & S0 49.618 W89 32.416 & 0.79 & 281 \\
\hline Playa Manglesito & San Cristobal & S0 49.493 W89 32.481 & 3.19 & 49 \\
\hline Playa Manglesito & San Cristobal & S0 49.493 W89 32.481 & 1.09 & 94 \\
\hline Playa Manglesito & San Cristobal & S0 49.493 W89 32.481 & 2.69 & 49 \\
\hline Playa Manglesito & San Cristobal & S0 49.455 W89 32.456 & 3.83 & 30 \\
\hline Isla Lobos & San Cristobal & S0 51.386 W89 33.932 & 1.5 & 25 \\
\hline Puerto Moreno & San Cristobal & S0 54.084 W89 36.702 & 2.16 & 46.9 \\
\hline Puerto Moreno & San Cristobal & S0 54.138 W89 36.829 & 2.23 & 25 \\
\hline Puerto Moreno & San Cristobal & S0 54.116 W89 36.836 & 2.23 & 0 \\
\hline Puerto Moreno & San Cristobal & S0 53.979 W89 36.558 & 2.56 & 23.5 \\
\hline Puerto Moreno & San Cristobal & S0 53.911 W89 36.568 & 2.52 & 36 \\
\hline Punta Pitt & San Cristobal & S0 42.802 W89 14.806 & 2.27 & 66.5 \\
\hline Punta Pitt & San Cristobal & S0 42.791 W89 14.839 & 1.49 & 75.6 \\
\hline Punta Pitt & San Cristobal & S0 42.715 W89 15.199 & 3.07 & 25 \\
\hline Punta Pitt & San Cristobal & S0 42.710 W89 15.209 & 1.79 & 61 \\
\hline Punta Pitt & San Cristobal & S0 42.666 W89 15.223 & 2.41 & 28 \\
\hline Punta Pitt & San Cristobal & S0 42.628 W89 15.232 & 2.62 & 33 \\
\hline Punta Pitt & San Cristobal & S0 42.566 W89 15.233 & 2.65 & 36.8 \\
\hline Punta Pitt & San Cristobal & S0 42.462 W89 15.214 & 2.3 & 61 \\
\hline Punta Pitt & San Cristobal & S0 42.451 W89 15.253 & 2.8 & 26 \\
\hline Punta Pitt & San Cristobal & S0 42.398 W89 15.287 & 3.35 & 39 \\
\hline Punta Pitt & San Cristobal & S0 42.398 W89 15.287 & 1.65 & 48.3 \\
\hline Punta Pitt & San Cristobal & S0 42.208 W89 15.303 & 3.58 & 34.8 \\
\hline Punta Pitt & San Cristobal & S0 42.208 W89 15.303 & 3.48 & 36.8 \\
\hline La Galapaguera & San Cristobal & S0 41.787 W89 18.013 & 1.67 & 52.3 \\
\hline La Galapaguera & San Cristobal & S0 41.793 W89 18.011 & 2.29 & 18.1 \\
\hline La Galapaguera & San Cristobal & S0 41.741 W89 18.091 & 3.44 & 13.1 \\
\hline La Galapaguera & San Cristobal & S0 41.720 W89 18.135 & 3.65 & 16.1 \\
\hline La Galapaguera & San Cristobal & S0 41.720 W89 18.135 & 2.85 & 16.1 \\
\hline La Galapaguera & San Cristobal & S0 41.692 W89 18.156 & 3.38 & 16 \\
\hline La Galapaguera & San Cristobal & S0 41.589 W89 18.190 & 2.02 & 15 \\
\hline La Galapaguera & San Cristobal & S0 41.576 W89 18.195 & 3.14 & 16.3 \\
\hline La Galapaguera & San Cristobal & S0 41.557 W89 18.207 & 3.06 & 18.3 \\
\hline Playa SC I & San Cristobal & S0 41.205 W89 20.818 & 2.13 & 13.3 \\
\hline Playa SC I & San Cristobal & S0 41.205 W89 20.818 & 1.33 & 22.3 \\
\hline Playa SC II & San Cristobal & S0 45.393 W89 27.294 & 3.86 & 15.3 \\
\hline Playa SC II & San Cristobal & S0 45.393 W89 27.294 & 2.76 & 15.3 \\
\hline Playa SC II & San Cristobal & S0 45.393 W89 27.294 & 2.96 & 15 \\
\hline
\end{tabular}


Table 1 continued

\begin{tabular}{|c|c|c|c|c|}
\hline Location & Island & Coordinates & Flow/runup elevation (m) & Inland distance $(\mathrm{m})$ \\
\hline Playa SC II & San Cristobal & S0 45.317 W89 27.243 & 2.02 & 13 \\
\hline Playa SC II & San Cristobal & S0 45.270 W89 27.186 & 3.39 & 16.2 \\
\hline Playa SC II & San Cristobal & S0 45.270 W89 27.186 & 3.59 & 16.2 \\
\hline Playa SC II & San Cristobal & S0 45.234 W89 27.155 & 3.17 & 15.2 \\
\hline Playa SC II & San Cristobal & S0 45.159 W89 27.085 & 3.53 & 20.1 \\
\hline Playa SC II & San Cristobal & S0 45.159 W89 27.085 & 2.63 & 20.1 \\
\hline Playa SAC I & Santa Cruz & S0 36.065 W90 32.252 & 1.95 & 15.3 \\
\hline Playa SAC II & Santa Cruz & S0 32.499 W90 30.647 & 4.73 & 29.6 \\
\hline Playa SAC II & Santa Cruz & S0 32.486 W90 30.649 & 4.76 & 29.5 \\
\hline Playa SAC II & Santa Cruz & S0 32.406 W90 30.716 & 2.42 & 22.6 \\
\hline Playa SAC II & Santa Cruz & S0 32.544 W90 30.646 & 3.97 & 22.3 \\
\hline Playa SAC II & Santa Cruz & S0 32.544 W90 30.646 & 3.37 & 22.3 \\
\hline Playa SAC III & Santa Cruz & S0 30.408 W90 24.887 & 3.84 & 14.4 \\
\hline Playa SAC III & Santa Cruz & S0 30.408 W90 24.887 & 2.94 & 14.4 \\
\hline Playa SAC III & Santa Cruz & S0 30.454 W90 24.929 & 2.65 & 12.6 \\
\hline Playa SAC III & Santa Cruz & S0 30.494 W90 25.015 & 2.04 & 10.4 \\
\hline Sombrero Chino & Santiago & S0 22.089 W90 35.048 & 2.27 & 28.5 \\
\hline Sombrero Chino & Santiago & S0 22.185 W90 35.118 & 0.51 & 16.5 \\
\hline Sombrero Chino & Santiago & S0 22.191 W90 35.126 & 0.64 & 17.4 \\
\hline Sombrero Chino & Santiago & S0 22.167 W90 35.095 & 1.72 & 28 \\
\hline Playa SA I & Santiago & S0 17.368 W90 33.977 & 0.8 & 53.5 \\
\hline Playa SA II & Santiago & So 13.004 W90 36.420 & 1.1 & 27 \\
\hline Playa SA II & Santiago & S0 13.004 W90 36.420 & 1.6 & 37.8 \\
\hline Playa SA II & Santiago & S0 13.031 W90 36.451 & 1.82 & 34.6 \\
\hline Playa SA II & Santiago & So 13.031 W90 36.451 & 1.42 & 26.3 \\
\hline Playa SA II & Santiago & S0 13.031 W90 36.451 & 1.02 & 22.9 \\
\hline Playa SA II & Santiago & So 13.011 W90 36.502 & 1.05 & 31.8 \\
\hline Playa SA II & Santiago & So 11.785 W90 39.024 & 2.39 & 34.2 \\
\hline Playa SA II & Santiago & S0 11.742 W90 38.923 & 1.74 & 30.1 \\
\hline Playa SA II & Santiago & S0 11.809 W90 39.086 & 2.9 & 49.9 \\
\hline Playa SA II & Santiago & So 11.833 W90 39.115 & 2.85 & 42.1 \\
\hline Playa SA II & Santiago & S0 11.833 W90 39.115 & 3.15 & 42.1 \\
\hline Playa IS I & Isabela & S0 36.728 W90 53.636 & 2.51 & 27.6 \\
\hline Playa IS I & Isabela & S0 36.794 W90 53.696 & 1.45 & 32.8 \\
\hline Playa IS I & Isabela & So 36.794 W90 53.696 & 1.95 & 207.5 \\
\hline Playa IS I & Isabela & S0 36.681 W90 53.655 & 1.8 & 12.7 \\
\hline Playa IS I & Isabela & S0 36.638 W90 53.642 & 4.63 & 24 \\
\hline Playa IS I & Isabela & S0 36.545 W90 53.653 & 2.26 & 23.9 \\
\hline Playa IS II & Isabela & S0 33.415 W90 57.311 & 3.91 & 17.5 \\
\hline Playa IS II & Isabela & S0 33.439 W90 57.328 & 1.64 & 52.9 \\
\hline Playa IS II & Isabela & S0 33.439 W90 57.328 & 1.74 & 142.1 \\
\hline Playa IS II & Isabela & S0 33.592 W90 57.380 & 2.1 & 14.6 \\
\hline Playa IS II & Isabela & S0 33.661 W90 57.390 & 2.44 & 4.7 \\
\hline Playa IS III & Isabela & S0 33.768 W90 57.755 & 4.99 & 7.9 \\
\hline Playa IS III & Isabela & So 33.769 W90 57.757 & 4.69 & 11.7 \\
\hline Black Turtle Beach & Isabela & S0 14.706 W91 23.198 & 3.25 & 22.8 \\
\hline Black Turtle Beach & Isabela & S0 14.706 W91 23.198 & 3.05 & 42.8 \\
\hline Black Turtle Beach & Isabela & S0 14.706 W91 23.198 & 0.45 & 103.5 \\
\hline Black Turtle Beach & Isabela & S0 14.594 W91 23.251 & 5.04 & 25.9 \\
\hline Urbina Bay & Isabela & S0 23.607 W91 13.673 & 2.54 & 8.6 \\
\hline Urbina Bay & Isabela & S0 23.607 W91 13.673 & 0.94 & 8.6 \\
\hline Urbina Bay & Isabela & S0 23.661 W91 13.740 & 2.22 & 18.8 \\
\hline Urbina Bay & Isabela & S0 23.558 W91 13.554 & 1.88 & 13.3 \\
\hline Urbina Bay & Isabela & S0 23.558 W91 13.554 & 0.78 & 111.4 \\
\hline Playa Tsunami & Isabela & S0 41.291 W91 15.013 & 4.8 & 23.6 \\
\hline Playa Tsunami & Isabela & S0 41.291 W91 15.013 & 5.7 & 23.6 \\
\hline Playa Tsunami & Isabela & S0 41.308 W91 15.051 & 6.12 & 15 \\
\hline
\end{tabular}


Table 1 continued

\begin{tabular}{lllll}
\hline Location & Island & Coordinates & Flow/runup elevation (m) & Inland distance (m) \\
\hline Playa Tsunami & Isabela & S0 41.285 W91 15.014 & 5.03 & 16.5 \\
Playa Rocks & Isabela & S0 41.259 W91 14.990 & 3.16 & 33.2 \\
Playa Rocks & Isabela & S0 41.259 W91 14.990 & 3.06 & 49 \\
Playa Rocks & Isabela & S0 41.211 W91 14.968 & 4.09 & 26 \\
Playa Rocks & Isabela & S0 41.161 W91 14.950 & 1.81 & 37.1 \\
Playa Rocks & Isabela & S0 41.161 W91 14.950 & 1.01 & 61.1 \\
Playa Rocks & Isabela & S0 41.071 W91 14.932 & 2.8 & 21.7 \\
Playa Rocks & Isabela & S0 41.071 W91 14.932 & 1 & 38.6 \\
Playa Rocks & Isabela & S0 40.924 W91 14.950 & 1.95 & 11.8 \\
Playa Rocks & Isabela & S0 40.914 W91 14.951 & 2.36 & 24.8 \\
Playa Rocks & Isabela & S0 40.914 W91 14.951 & 1.46 & 92.5 \\
Playa Rocks & Isabela & S0 40.914 W91 14.951 & 0.96 & 28.7 \\
Puerto Villamil & Isabela & S0 57.479 W90 57.944 & 1.12 & 15.1 \\
Puerto Villamil & Isabela & S0 57.468 W90 58.015 & 1.62 & 26.5 \\
Puerto Villamil & Isabela & S0 57.478 W90 57.913 & 1.3 & \\
\hline
\end{tabular}

\section{REFERENCES}

ABE, K. (1979). Size of great earthquakes of 1837-1979 inferred from tsunami data, J. Geophys. Res. 84, 1561-1568.

Arcos, M., Macinnes, B., Arreaga, P., Rivera-Hernandez, F., Weiss, R., and Lynett, P., "A Meter-Thick Sedimentary Package Caused By the 2011 Tohoku Tsunami in El Garrapatero, Galapagos-A Record of Sedimentary Deposition Enabled by Tsunami Erosion," in review for Quaternary Research, 2012.

Balley, K., 1976. Potassium-Argon Ages from the Galápagos Islands. Science 192, 465-467.

Borrero, J., Rob Bell, Claudia Csato, Willem Delange, Derek Goring, S. Dougal Greer, Vernon Pickett, and William Power Observations, Effects and Real Time Assessment of the March 11, 2011 Tohoku-oki Tsunami in New Zealand, Pure Appl. Geophys. doi:10.1007/s00024-012-0492-6.

Dominey-Howes, D., Dengler, L., Dunbar, P., Kong, L., Fritz, H., Imamura, F., McAdoo, B., Satake, K., Yalciner, A., Yamamoto, M., Yulianto, E., Koshimura, S., and Borrero, J. (2012). International Tsunami Survey Team (ITST) Post-Tsunami Survey Field Guide. 2nd Edition. UNESCO-IOC, Paris.

KanAmori, H., and K. McNally Variable rupture mode of the subduction zone along the Ecuador-Colombia coast, Bull. Seismol. Soc. Am., 72,. 1241-1253, 1982.

Kanoglu, U. and Synolakis, C.E., 1998, Long wave runup on piecewise linear topographies, Journal of Fluid Mechanics, 374, 1-28.

KIM, D.-H. and LynetT, P. (2011) "Turbulent Mixing and Scalar Transport in Shallow and Wavy Flows." Physics of Fluids, v. 23 (1), doi:10.1063/1.3531716 (16 pages).

Liu, P. L.-F., Y-S. Cho, M.J. Briggs, C.E. Synolakis, and U. KANOGLU Run-up of solitary waves on a circular island. J. Fluid Mech, 302:259-285, 1995.

LyNETT, P. (2007). "The Effect of a Shallow Water Obstruction on Long Wave Runup and Overland Flow Velocity." Journal of
Waterway, Port, Coastal, and Ocean Engineering (ASCE), v. 133(6), p. 455-462.

Lynett, P., Borrero, J, Weiss, R., Son, S., Greer, D., and Renteria, W. "Observations and Modeling of Tsunami-Induced Currents in Ports and Harbors," Earth and Planetary Science Letters, v. 327/ 328, pp. 68-74, doi:10.1016/j.eps1.2012.02.002, 2012.

Mori, N., Takahashi, T., Yasuda, T. and Yanagisawa, H., (2011) Survey of the 2011 Tohku earthquake tsunami inundation and run-up. Geophys. Res. Lett. doi:10.1029/2011GL049210.

Shiki, T., Tsuji, Y., Minoura, K., and Yamazaki, T. (eds) Tsunamiites - Features and Implication, $1^{\text {st }}$ edition, (Elsevier Science, 2008).

Son, S., Lynett, P., and Kim, D.-H. (2011) "Nested and MultiPhysics Modeling of Tsunami Evolution from Generation to Inundation." Ocean Modelling, v. 38 (1-2), p. 96-113, doi: 10.1016/j.ocemod.2011.02.007.

Synolakis, C. Е. \& OKaL, Е. А. 2005 1992-2002: perspective on a decade of post tsunami surveys. Adv. Nat. Technol. Hazards 23, $1-30$.

USGS, 2011. Finite Fault Model, Updated Result of the Mar 11, 2011 Mw 9.0 Earthquake Offshore Honshu, Japan. http:// earthquake.usgs.gov/earthquakes/eqinthenews/2011/usc0001xgp/ finite_fault.php.

Werner, R., Hoernle, K., Barckhausen, U., Hauff, F., 2003. Geodynamic evolution of the Galápagos hot spot system (Central East Pacific) over the past 20 m.y.: Constraints from morphology, geochemistry, and magnetic anomalies. Geochem. Geophys. Geosyst. 4, 28 PP.

Wessel, P. and W. H. F. Sмith, (1991) Free software helps map and display data, EOS, Trans. AGU, 72, 441.

Wilson, R., Admire, A., Borrero, J., Dengler, L., LegG, M., Lynett, P., Miller, K., Ritchie, A., Sterling, K., and Whitmore,P. (2012). Observations and Impacts from the 2010 Chilean and 2011 Japanese tsunamis in California. Pure Appl. Geophys. doi:10.1007/s00024-012-0527-z. 